\title{
Academic Stress among Government and Private High School Students
}

\author{
Dr. Smritikana Mitra Ghosh ${ }^{1}$
}

\section{ABSTRACT}

Objectives: 1) To find out whether there is significant difference between the government and private school students. 2) To study the gender difference with regard to academic stress among high school students. Hypotheses: 1) There is significant mean difference between government and private school students with respect to academic stress. 2) There is significant mean difference between male and female students with respect to academic stress. Sample: Sample of the present study consistent 200 high school students from different schools of Ranchi town. One hundred students were government's high school (male and female) and one hundred were private high school (male and female). Tools: Bisht battery of stress scales developed by Bisht (1987) was used to collect data. Result: The data have been analysed according to objectives and hypotheses of the research .It was observed that students in private schools have more academic stress than their counterparts in government schools. Female students experienced higher academic stress than male students.

Keywords: Academic Stress; High school students

Stress has become an important topic in academic circle as well as in our society. Many scholars in the field of behavioural science have carried out extensive research on stress and its outcomes and concluded that the topic needed more attention. Stress and anxiety in children and teenagers are just as prevalent as in adults. Negligence of parents, high expectations in academic or other performances, abused childhood, growing up tensions and demand for familial responsibility etc. the main causes of childhood and teen stress. Parents, who are not emotionally available for their children or lack positive coping mechanisms themselves, often spur stress in their offspring. Academic stress is mental distress with respect to some anticipated frustration associated with academic failure or even unawareness to the possibility of such failure. Students have to face many academic demands, for example, school examination, answering questions in the class, showing progress in school subjects. Understanding what the teacher is teaching, competing with other class mates, fulfilling teachers and parents academic expectations. These demands may tax or exceed available resources of the students. As a consequence, they can be under stress, since

\footnotetext{
${ }^{1}$ Ph.D, Ranchi University, Ranchi, Jharkhand \& India

*Responding Author

(c) 2016 I S Ghosh; licensee IJIP. This is an Open Access Research distributed under the terms of the Creative Commons Attribution License (http://creativecommons.org/licenses/by/2.0), which permits unrestricted use, distribution, and reproduction in any Medium, provided the original work is properly cited.
} 
the demand is related to achievement of an academic goal. So, academic related to the achievement of an academic goal. Bisht (1989) has defined academic stress as a demand related to academics that tax or exceed the available resources (internal or external) as cognitively appeared by the student involved. According to her, academic stress reflects perception of individual's academic frustration, academic conflict, academic pressure and academic anxiety. She has given the definition of four components of academic stress as follows: Academic Frustration:- Academic frustration is a state caused by harm of some academic goals. Academic Conflict:- Academic Conflict is the result of two or more qua] hut in compatible response tendencies to academic goals. Academic Pressure:- When the student is under heavy demands of time and energy to meet academic goals. Academic Anxiety:- Apprehension of harm to some academic goals.

Academic Stress is an important factor accounting for variation in academic achievement. It also contributes to major mental health hazards, problems both physical and mental stress related diseases. Stress makes a significant contribution to the prediction of subsequent school performance and act as a negative predictor of academic performance in school children shows the components of Academic Stress Hussain. Academic Stress is a mental stress with respect to some anticipated frustration associated with academic failure or even an awareness of possibility of such behaviour (Gupta and Khan, 1987).

Academic stress is often the result of the combination of the demands a youngster places on himself or his ability (or 'perceived' ability) and the pressures that come from outside sources such as family, friends or school. The pressure one place on himself is the most significant as there is often a discrepancy between what one thinks he ought to be doing and what he actually does.

\section{CAUSES OF ACADEMIC STRESS}

- Academics - Alphabetically first among the causes of stress on students is academic pressure. Simply tackling more difficult assignments can demand stress management techniques. It might be wise for teachers to introduce students to this stress with an assignment such as a "Causes of Stress on Students Essay”. Requiring students to interview older students and educators, as well as research the Internet on the subject, could help them prepare for the stresses of academic challenges.

- Parental Pressure - Finally, students at either level experience stress from parental pressures. Parents want their children to succeed in school. They want to see good grades, but they also want to see success in life's other areas. In their attempts to guide their children, parents can become one of the major causes of stress on students. It is wise for parents and others who work with students to take time to recognize the stresses students face, if they then provide stress management techniques, they will do much to relieve and encourage their students.

- Environment - The school environment itself can be a cause of stress on students. Students moving into secondary education find it challenging to constantly move around to classes. 


\section{Academic Stress among Government and Private High School Students}

Those matriculating to tertiary education are challenged with leaving home and establishing a new life in new setting. Both can cause stress on students.

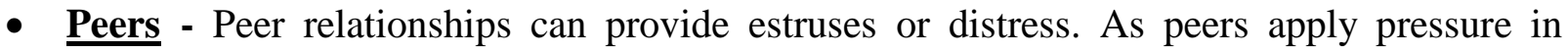
regard to dress, behavior, choice of friends or sic, and many other areas of life, that pressure can become a huge presence of stress on students.

\section{REVIEW OF RELATED LITERATURE}

Academic stress is the product of a combination of academic related demands that exceed the adaptive resources available to an individual. Bartwal and Raj (2014) observed no significant gender differences with regard to academic stress and social intelligence among rural and urban adolescents but significant correlation was found between Academic stress and Social intelligence of rural and urban adolescents. Mathew and Jayan (2006) found no difference between boys and the girls of the age group of 15-17 years with respect to their Academic stress. Both experienced more or less similar level of academic stress and employed similar kinds of coping styles. Husain, Kumar and Husain (2008) explored the level of academic stress and overall adjustment among Public and Government high school students and also examined the relationship between academic stress and adjustment. Results indicated that magnitude of academic stress was significantly higher among the Public school students where as Government school students were significantly better in terms of their levels of adjustment. Misra and McKean (2000) conducted a study surveying 249 college students at a Midwestern university. The study showed that anxiety, ineffective time management and a lack of satisfying activities outside of academia were strong predictors of academic stress. The study also showed that while female students managed their time more effectively than male students, they also experienced the highest levels of stress and anxiety. Academic stress can be the ultimate career stopper. Huan, et.al (2005) investigated the role of optimism together with gender, on students' perception of academic stress. Four hundred and thirty secondary school students from Singapore participated in this study and data were collected using two self-report measures: the Life Orientation Test and the Academic Expectations Stress Inventory. Results showed a significant negative relationship between optimism and academic stress in students. Gender was not a significant predictor of academic stress and no two-way interactions were found between optimism and gender of the participants. Neelam and Attri (2013) have attempted to find out the academic stress and academic achievement of secondary school students. It was hypothesized that there exists a significant difference in academic anxiety and academic achievement of male and female secondary school students. For verification of these hypotheses, the data was collected from 200 secondary school students of Mandi district of Himachal Pradesh by adopting lottery method of random sampling by administering 'Academic Anxiety Scale for Children (AASC)' and their marks of class 9th were taken as academic achievement. The statistical technique used was $\mathrm{t}$ - test. The findings of the present study revealed that there exists significant difference in academic anxiety and academic achievement of male and female secondary school students. Girls found to be more academically anxious and had better academic achievement than boys. 


\section{METHODOLOGY}

The aim of this section is to clarify the methodology of this research. This gives an account of the objectives, hypotheses, research sample, and the research tool that were used for data collection.

\section{Statement Of The Problem}

'Academic Stress among Government and Private High School Students'.

\section{Objectives}

- To find out whether there is significant difference between the government and private school students.

- To study the gender difference with regard to academic stress among high school students.

Hypotheses

- There is significant mean difference between government and private school students with respect to academic stress.

- There is significant mean difference between male and female students with respect to academic stress.

\section{Sample}

The study was conducted on a group of $(200) 10^{\text {th }}$ grade adolescent students from four schools two government and two private in Ranchi town. Out of 200 students, 100 were taken from government school (50 male +50 female) and the remaining 100 were taken from private school (50 male +50 female).

\section{Variables}

1. Dependent variable: Academic Stress.

2. Independent variables: Types of school and Gender

\section{Research Tool}

BISHT BATTERY OF STRESS SCALES (SCALE OF ACADEMIC STRESS -SAS) -This battery of stress scales was developed by Bisht (1987). It measures exclusive stress types having all the four components of stress, i.e., frustration, conflict, pressure and anxiety in them. This battery consists of thirteen scales which measures thirteen types of stresses viz., Existential Stress, Achievement Stress, Academic Stress, Self-Concept Stress, Self- Actualization Stress, Physical Stress, Social Stress, Role Stress, Institutional Stress, Family Stress, Financial Stress, Vocational Stress and Superstition Stress. Of these thirteen scales, the Scale of Academic Stress will be used. There are total 80 items in the Scale of Academic Stress. The battery of scale is in Hindi and the age group on which it was standardized is $13+$ to 17 years. The internal consistency reliability coefficient of SAS is .88. 


\section{Statistical Techniques}

Statistical analysis was done by applying Mean (M), Standard Deviation (SD) and t-test.

\section{RESULTS AND DISCUSSIONS}

To attain the objective of the study and to verify the formulated hypotheses the data were analyzed. To meet out the purpose of the study mean, SD was calculated. ' $t$ ' value was calculated to test the significant difference between the means of the groups.

Table 1: Comparison of academic stress among government and private high school students

\begin{tabular}{|l|l|l|l|l|l|l|}
\hline Group & N & Mean & SD & Md & t-value & $\begin{array}{l}\text { Level of } \\
\text { significance }\end{array}$ \\
\cline { 1 - 5 } Government School students & 100 & 271.52 & 87.62 & & & \\
\cline { 1 - 5 } Private School students & 100 & 299.69 & 93.76 & 28.17 & 2.19 & 0.05 \\
\hline
\end{tabular}

Figure 1: Mean scores of government and private high school students on academic stress

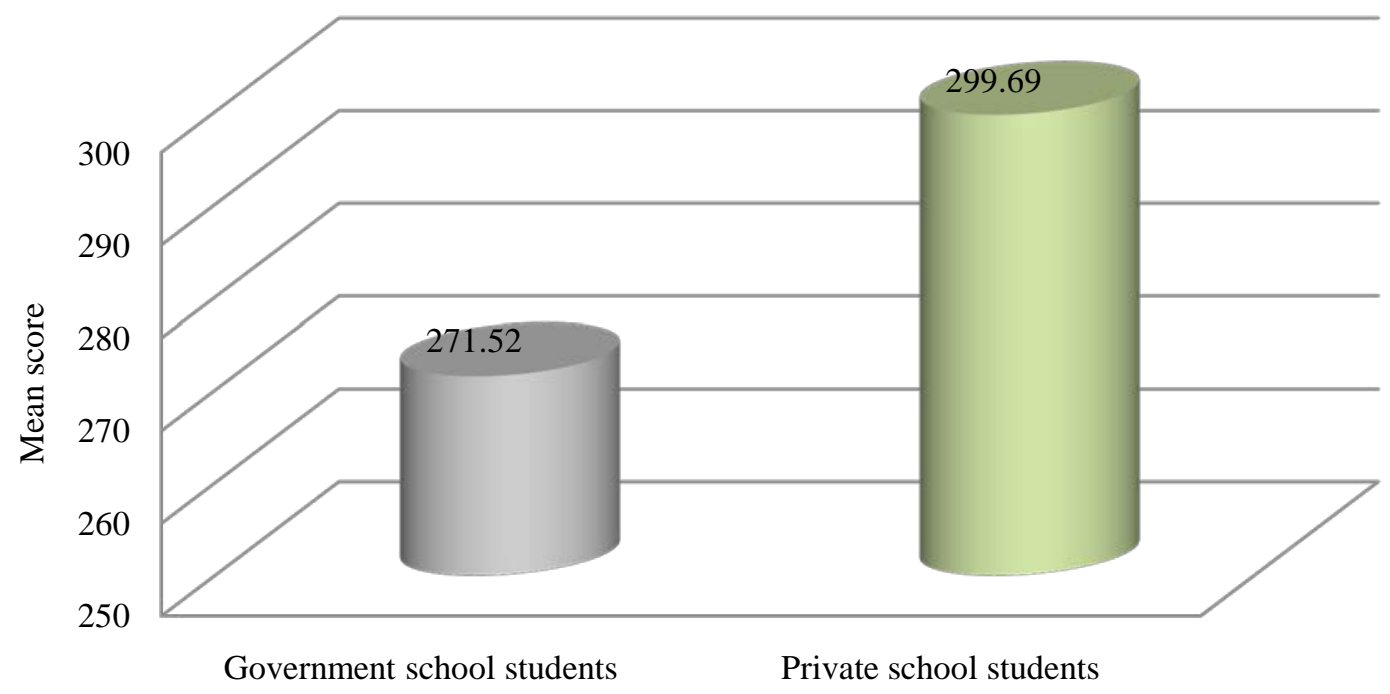

Table 1 and figure 1 indicates that adolescents studying in government schools had mean academic stress score of 271.52 and adolescents of Private schools had mean score of 299.68. The observed t value was 2.19 which was found to be significant at 0.05 level. It can be said that there exists significant difference between the groups under study on academic stress measure. It is quiet clear that adolescents in private schools have more academic stress than their counterparts in government schools similar to the findings of Hussain et al (2008). 
Table 2: Comparison of academic stress among male and female high school students

\begin{tabular}{|l|l|l|l|l|l|l|}
\hline Group & N & Mean & SD & Md & t-value & $\begin{array}{l}\text { Level of } \\
\text { significance }\end{array}$ \\
\hline Male & 100 & 270.74 & 85.74 & \multirow{2}{*}{43.74} & 3.18 & 0.01 \\
\hline Female & 100 & 314.48 & 107.33 & & & \\
\hline
\end{tabular}

Figure 2: Mean scores of male and female high school students on academic stress

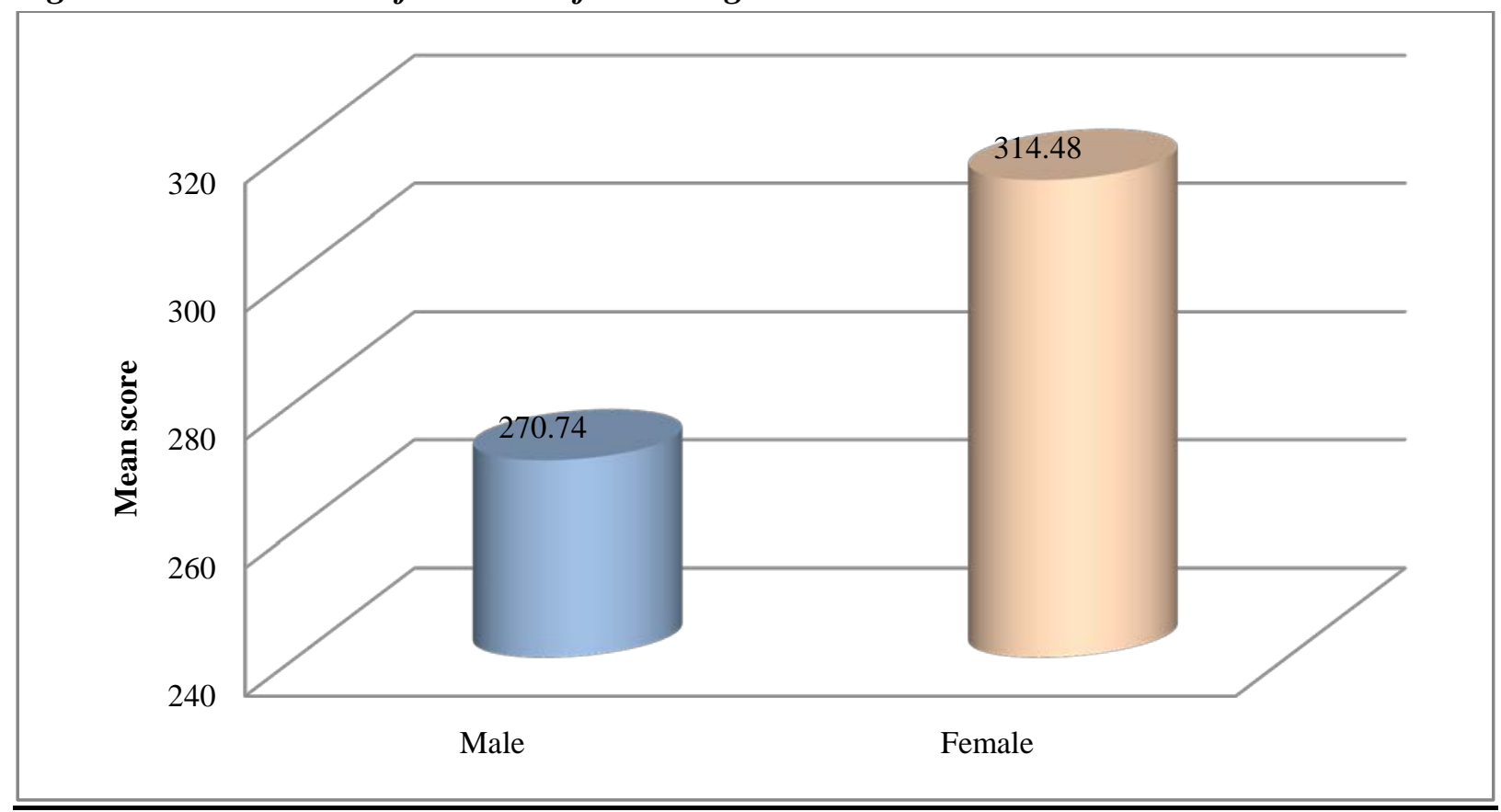

Table. 2 and figure 2 indicates that the mean score of male adolescents was 270.74 whereas mean score of female adolescents was 314.48. The calculated ' $t$ ' value comes out to be 3.18. When compared with table value, it indicates that the calculated value was higher than the table value 2.60 with df 200 at 0.01 level of significance. So the mean difference was significant. Female subjects were found to be under more academic stress as compared to their male counterparts. This may be due to the fact that females are sensitive \& sincere by nature and take everything very seriously whereas males are generally easy going and happy go lucky.

\section{CONCLUSIONS}

As academic stress was found to be more prominent among the students of private school than government school. From the findings it may also be concluded that, female students experienced more academic stress than their male counterparts. 


\section{LIMITATIONS OF THE STUDY}

The sample of the study was too small. This finding cannot be generalized. Another limitation is the sample consisted of high school students only.

\section{SUGGESTIONS FOR FURTHER STUDY}

This research study was conducted on the adolescents of high schools. It is suggested that the same research may be conducted from primary level up to university level. Future research should use larger sample size.

\section{REFFERENCES}

Attri, A.K \& Neelam (2013). "Academic Anxiety and Academic Achievement of Secondary School Students - A Study on Gender differences”International Journal of Behavioural Social and Movement Science. 2, 1.

Bartwal, R. S. \& Raj, A. (2014). Academic stress among school going adolescents in relation to their social intelligence. Indian Streams Research Journal, 4(2), 1-6.

Gupta, K. \& Khan, B. (1987). Anxiety levels as factors in concept formation, Indian Journal of Psychological Report, 31:187-192.

Huan, V.S, Yeo, L.S, Ang, R.P, \& Chong, W.H. (2005).The influence of dispositional optimism and gender on adolescents perceptions' perception of academic stress. Adolescence, 41,533-546.

Hussain, A., Kumar, A. \& Husain, A. (2008). Academic stress and adjustment among high school students. Journal of the Indian academy of Applied Psychology, 34, 70-73.

Mathew, B \& Jayan, C. (2006). Academic stress and coping styles among plus-two students. Indian Psychol. Rev., 66(1): 41-48

Misra, R \& McKean, M. (2000). College Students' Academic Stress and its Relation to their anxiety, time management, and leisure Satisfaction, Am. J. Health Stud. 16(1): 41-51. 